\title{
Relationship Between Arm Span Measurements and Body Height in Berane
}

\author{
Milena Mitrovic ${ }^{1}$ \\ 'University of Montenegro, Faculty for Sport and Physical Education, Niksic, Montenegro
}

\begin{abstract}
The aim of this study was to determine whether the arm span predicted body height. The sample of respondents was 89 adolescents from Berane, 52 boys and 37 girls. The boy's average was 17.96 years, and the girl was 18.08 years. After measuring the height and arm span, the central and dispersive parameters for both variables are calculated. The average height of the boys is $182.85 \pm 6.55 \mathrm{~cm}$ and the arm span is $181.04 \pm 6.20 \mathrm{~cm}$. The average height of the girls is $169.23 \pm 9.89 \mathrm{~cm}$ and the arm span is $167.48 \pm 6.39 \mathrm{~cm}$. The ratio of body height and arm span was determined by correlation coefficients with a confidence level of $95 \%$. In the end, regression analysis showed whether the arm span predicted body height. The results showed high coefficients of correlation and a large percentage of explained variability, which means that the arm span reliably predicts the height of the body.
\end{abstract}

Key words: Body height, Arm span, Adolescents, Berane

\section{Uvod}

Berane je grad koji se nalazi na sjeveru Crne Gore. Leži na rijeci Lim. Omeđeno je visoravnima između vrhova Bjelasice na zapadu, Cmiljevice na istoku, Tivranske klisure na sjeveru i Sutjeske i Previje na jugu. Berane ima veoma povoljan saobraćajno-geografski položaj, jer je magistralnim putem povezano sa Srbijom, a preko Rožaja i Čakora sa Kosovom i Metohijom. Dolinom Lima je takođe povezano magistralnim putem sa južnim dijelom Srbije i jugozapadnim dijelom Bosne i Hercegovine, a od Bijelog Polja i željeznicom.

Berane ima solidne uslove za razvoj sporta. Gradski stadion u Beranama ima kapacitet od 11000 mjesta, što ga čini drugim najvećim stadionom u Crnoj Gori, a izdvaja se atletskom stazom.

Broj stanovnika, prema popisu iz 2003. godine, iznosio je 11 776, što čini Berane šestim gradom po broju stanovnika u Crnoj Gori. U Beranama živi 8645 punoljetnih stanovnika, a prosječna starost stanovništva iznosi 34.9 godina (33.5 kod muškaraca i 36.2 kod žena). Predmet ovog istraživanja bili su adolescenti iz Berana.

Tjelesna visina je varijabla koja je vrlo često predmet mjerenja u fizičkoj kulturi. Tjelesnu visinu nije moguće uvijek pre-

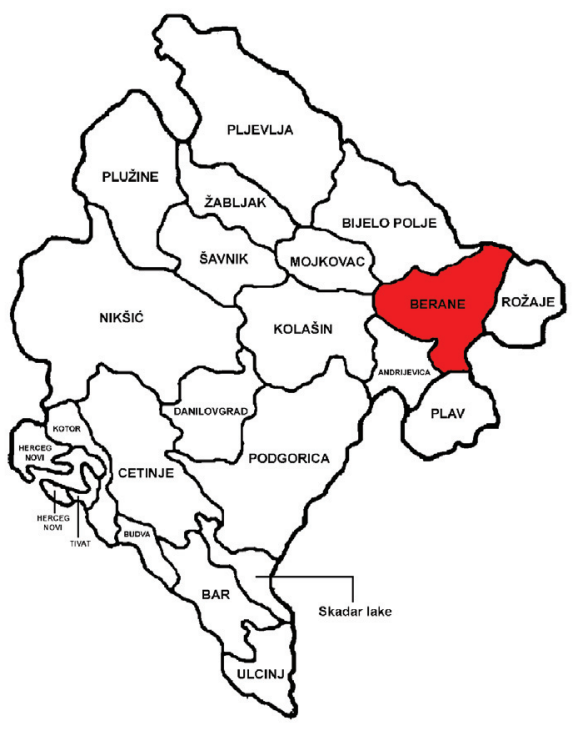

Slika 1. Opština Berane na karti Crne Gore

cizno odrediti, usljed raznih deformiteta. Zbog toga se koriste drugi indikatori za određivanje tjelesne visine kao što su dužina

Correspondence:

Montenegrro M.Mitrovic

Sport University of Montenegro, Faculty for Sport and Physical Education, Narodne omladine bb, 81400, Niksic, Montenegro E-Mail: milenam1054@gmail.com 
ruke i stopala, dužina tibije, visina koljena, dužina podlaktice, dužina grudne kosti, sjedeća visina, dužine lopatice, dužina ruke i drugo (Popovic, 2017; Gardasevic, Rasidagic, Krivokapic, Corluka, \& Bjelica, 2017). S obzirom na postojanje velikog broja indikatora, za određivanje visine tijela potrebno je koristiti one najpreciznije. Tako je, na osnovu većeg broja istraživanja na teritoriji Kosova, utvrđeno da su dužina tibije, dužina stopala, stojeća i sjedjeća visina imaju prediktivnu vrijednost kada je u pitanju tjelesna visina, ali da najpouzdanije rezultate daje raspon ruku ruku (Gardašević, 2018; Gardasevic, Masanovic, Arifi, 2018a; Gardasevic, Masanovic, Arifi, 2018b; Gardasevic, Masanovic, Arifi, 2018c; Masanovic, 2018c; Masanovic, Gardasevic, \& Arifi, 2018d; Masanovic, Gardasevic, \& Arifi, 2018e; Masanovic, Gardasevic, \& Arifi, 2018f; Masanovic, Gardasevic, \& Arifi, 2018g; Popovic, Arifi, \& Bjelica, 2017a; Popovic, \& Bjelica, 2017; Popovic, Gardasevic, Masanovic, Arifi, \& Bjelica, 2017b; Masanovic, 2018b; Gardašević, 2018b; Masanovic, 2018a; Masanovic, Gardasevic, \& Arifi, 2018a; Masanovic, Gardasevic, \& Arifi, 2018b; Masanovic, Gardasevic, \& Arifi, 2018c ). Takođe, istraživanja su pokazala i da odnosi dugih kostiju i visine razlikuju s obzirom na etničku pripadnost (Bjelica, Popovic, Kezunovic, Petkovic, Jurak, G., \& Grasgruber, 2012; Brown, Feng, \& Knapp, 2002; Popovic, Bjelica, Tanase, \& Milasinovic, 2015; Popovic, \& Bjelica, 2016; Popović, Bjelica, Petković, Muratović, \& Georgiev, 2014; Popović, Bjelica, Milašinović, Gardašević, \& Rašidagić, 2016; Reeves, Varakamin, \& Henri, 1996; Steele \& Chenier, 1990). S obzirom da u istoj državi, imamo pripadnike različitih etničkih zajednica, odnos visine tijela i dugih kostiju se i kod njih takođe razlikuje (Arifi, 2017a; Arif, Bjelica, Sermaxhaj, Gardasevic, Kezunovic, \& Popovic, 2017b; Arifi, Sermaxhaj, Gardasevic, Iber Alaj, \& Metaj; Milašinović, Popović, Bjelica, \& Vasiljević, 2016; Popovic,2016; Gardasevic, Masanovic, \& Arifi, 2018d; Arifi, Gardasevic, \& Masanovic, 2018).

Još u prošlom vijeku je visina Crnogoraca bila zanimljiva naučnicima za proučavanje. Prema nekim istraživanjima, početkom XX vijeka Crnogorci su bili najviši narod na svijetu (Ehrich, 1946). Prema novijim istraživanjima, Crnogorci su drugi najviši narod na svijetu, poslije Holanđana (Grasgruber, Sebera, Hrazdira, Cacek, \& Kalina, 2016). Prosječna visina muškaraca u Crnoj Gori iznosi $183.21 \pm 7.06 \mathrm{~cm}$, dok njihov raspon ruku prosječno iznosi $185.71 \pm 8.17 \mathrm{~cm}$. Prosječna visina žena u Crnoj Gori iznosi $168.37 \pm 5.27 \mathrm{~cm}$ sa rasponom ruku od $168.13 \pm 6.58 \mathrm{~cm}$. U istraživanjima sprovedenim $\mathrm{u}$
Crnoj Gori dobijene su su procjene koje su suštinski drugačije $\mathrm{u}$ odnosu na druge populacije, što potvrđuje potrebu za izradom posebnih modela visine za svaku populaciju zbog etničkih razlika (Bjelica i sar., 2012). Takođe, smatra se da su uslovi života u razvijenoj zemlji kao što je Holandija uticali na to da Crnogorci izgube prvo mjesto u svijetu što se tiče visine, ali sa podizanjem standarda, velika je vjerovatnoća da će Crnogorci opet biti najvisočija nacija na svijetu.

Cilj ovog rada je utvrditi da li raspon ruku pouzdano predviđa tjelesnu visinu kod adolescenata iz Berana.

\section{Metod rada}

Uzorak ispitanika u okviru istraživanja sačinjavalo je 89 adolescenata iz Berana. Uzorak je podijeljen na dva subuzorka, po kriterijumu pola (tabela 1). Prvi subuzorak su činile osobe muškog pola $(\mathrm{n}=52)$, a drugi osobe ženskog pola $(\mathrm{n}=37)$. Prosječna starost osoba muškog pola je $17.96 \pm 0.15$ godina, a osoba ženskog pola $18.08 \pm 0.10$ godina.

$\mathrm{U}$ istraživanje nijesu bili uključeni adolescenti koji žive izvan teritorije Berana i ne pripadaju navedenom uzrastu. Takođe, u istraživanju nijesu učestvovali adolescenti sa tjelesnim deformitetima, zbog kojih se ne bi mogla precizno izmjeriti tjelesna visina i raspon ruku.

Mjerioci su izmjerili odabrane varijable, pridržavajući se propisanog ISAK priručnika. Podaci su obrađeni korišćenjem Statističkog paketa za društvene nauke (SPSS.20). Standardna devijacija (SD) je izračunata za obije antropometrijske varijable. Upoređivanje varijabli za rast i širinu ruku između subuzoraka je izvršen korišćenjem t-testa. Odnos između tjelesne visine i raspona ruke određen je korišćenjem koeficienta korelacije u intervalu pouzdanosti od 95\%. Na kraju je linearnom analizom utvrđeno sa kolikom pouzdanošću raspon ruku može predvidjeti tjelesnu visinu. Nivo značajnosti je postavljen na $\mathrm{p}<0.05$.

\section{Rezultati}

U Tabeli 1. su prikazani rezultati centralnih i disperzivnih parametara za oba uzorka. Aritmetička sredina za tjelesnu visinu kod ispitanika muškog pola iznosi $182.85 \pm 6.55$, a za raspon ruku $181.04 \pm 6.20 \mathrm{~cm}$. Kod ispitanika muškog pola tjelesna visina je manja $1.81 \pm 0.45 \mathrm{~cm}$ u odnosu na raspon ruku. Aritmetička sredina za tjelesnu visinu kod ispitanika ženskog pola iznosi $169.23 \pm 9.89 \mathrm{~cm}$, a za raspon ruku $167.48 \pm 6.39 \mathrm{~cm}$. Raspon ruku kod ispitanika ženskog pola je manji $1.75 \pm 3.5 \mathrm{~cm}$

Tabela 1. Centralni i disperzivni parametri antropometrijskih karakteristika

\begin{tabular}{ccc}
\hline Ispitanici & $\begin{array}{c}\text { Tjelesna visina(cm) } \\
\text { (AS } \pm \text { SD) }\end{array}$ & $\begin{array}{c}\text { Raspon ruku(cm) } \\
\text { (AS } \pm \text { SD) }\end{array}$ \\
\hline \multirow{2}{*}{ Muški } & $171.0-196.0$ & $169.0-194.0$ \\
& $(182.85 \pm 6.55)$ & $(181.04 \pm 6.20)$ \\
\multirow{2}{*}{ Ženski } & $160.0-179.0$ & $156.0-176.0$ \\
& $(169.23 \pm 9.89)$ & $(167.48 \pm 6.39)$ \\
\hline
\end{tabular}

u odnosu na visinu. Da bi se utvrdilo da li postoje statistički značajne razlike između subuzoraka u navedene dvije varijable, korisćen je t-test. Utvrđeno je da postoje statistički značaj- ne razlike između subuzoraka za obije varijable u korist osoba muškog pola sa koeficijentima $\mathrm{t}=10.066 \mathrm{i}$ Sig $=0.000$ za tjelesnu visinu i $\mathrm{t}=10.035$ i Sig=0.000 za raspon ruku.

Tabela 2. Korelaciona analiza između tjelesne visine i raspona ruku

\begin{tabular}{cccc}
\hline Ispitanici & Koeficijent korelacije & $\begin{array}{c}\text { Interval pouzdanosti } \\
\text { od 95\% }\end{array}$ & Nivo značajnosti \\
\hline Muški & 0.890 & $0.845-0.934$ & 0.000 \\
Ženski & 0.789 & $0.749-0.828$ & 0.000 \\
\hline
\end{tabular}


Korelacija između tjelesne visine i raspona ruku prikazana je u Tabeli 2. Korišćen je interval pouzdanosti od 95\%. Povezanost između tjelesne visine i raspona ruku je statistički značajna kod oba subuzorka na nivou $\mathrm{p}<0.000$. Koeficijenti korelacije su visoki i iznose 0.890 kod ispitanika muškog pola i 0.789 kod ispitanika ženskog pola.

U Tabeli 3. su prikazani rezultati regresione analize. Koeficijenti regresije su identični koeficijentima korelacije.

Tabela 3. Rezultati linearne regresione analize

\begin{tabular}{cccccc}
\hline Ispitanici & $\begin{array}{c}\text { Koeficijent } \\
\text { regresije }\end{array}$ & $\begin{array}{c}\text { Standardna } \\
\text { greška }\end{array}$ & $\begin{array}{c}\text { Koeficijent } \\
\text { determinacije (\%) }\end{array}$ & $\begin{array}{c}\text { t } \\
\text { vrijednost }\end{array}$ & $\begin{array}{c}\text { Nivo } \\
\text { značajnosti }\end{array}$ \\
\hline Muški & 0.890 & 4.405 & 71.2 & 9.781 & 0.000 \\
Ženski & 0.789 & 3.905 & 63.1 & 8.671 & 0.000 \\
\hline
\end{tabular}

Nivo značajnosti kod oba subuzorka iznosi 0.000 što znači da je predikcija tjelesne visine na osnovu raspona ruku statistički značajna. To se može zaključiti i na osnovu koeficijenata determinacije, kojim se kod osoba muškog pola može objasniti $71.2 \%$ varijabiliteta, a kod osoba ženskog pola $63.1 \%$. Ostali dio varijabiliteta je neobjašnjen, odnosno pod uticajem drugih faktora koji nijesu obuhvaćeni ovim istraživanjem.

Tjelesna visina i raspon ruku oba subuzorka, kao i njihova povezanost prikazani su skater dijagramom (Slika 2).

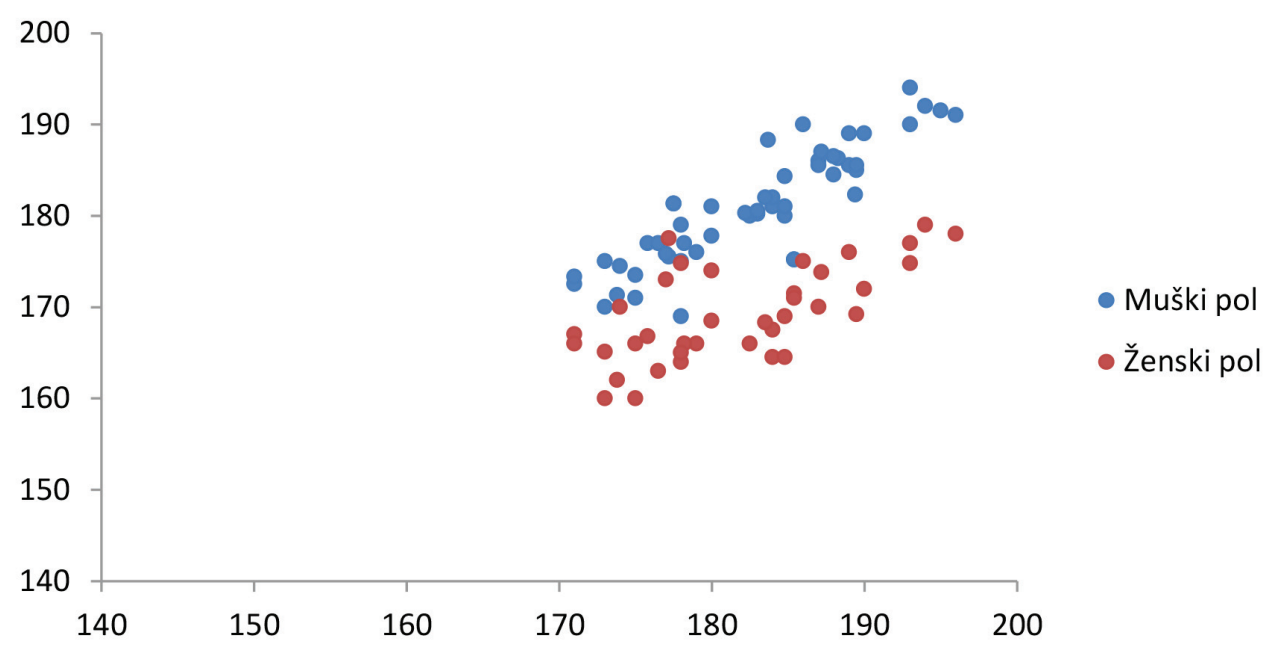

Slika 2. Skater dijagram koji pokazuje tjelesnu visinu i raspon ruku obije grupe ispitanika, kao i njihovu povezanost

\section{Diskusija}

U navedenom istraživanju, prosječna tjelesna visina adolescenata muškog pola iz Berana iznosi $182.85 \mathrm{~cm}$, dok je njihov prosječan raspon ruku $181.04 \mathrm{~cm}$. Prosječna tjelesna visina adolescenata ženskog pola iz Berana iznosi $169.23 \mathrm{~cm}$, dok je njihov prosječan raspon ruku $167.48 \mathrm{~cm}$. Kod oba pola tjelesna visina je veća od raspona ruku (kod adolescenata muškog pola za $1.81 \mathrm{~cm}$, a kod adolescenata ženskog pola za $1.78 \mathrm{~cm}$ ). U ranijim istraživanjima sprovedenim u Crnoj Gori, utvrđeno je da su najvisočiji adolescenti iz centralne regije, zatim iz sjeverne i na kraju iz južne regije. Prosječna visina adolescenata muškog pola iz sjeverne regije iznosi $183.01 \mathrm{~cm}$, a ženskog pola $168.84 \mathrm{~cm}$ (Popovic i sar., 2017). Ukoliko uporedimo rezultate dobijene $u$ ovom istraživanju sa navedenim, uočićemo da su adolescenti muškog pola nešto manji u odnosu na prosjek (za $0.16 \mathrm{~cm}$ ), dok su adolescenti ženskog pola visočiji od prosjeka (za $0.39 \mathrm{~cm})$. Kao što smo već rekli, prosječna visina muškaraca u Crnoj Gori iznosi $183.21 \mathrm{~cm}$, a žena $168.13 \mathrm{~cm}$ (Bjelica i sar., 2012). Primjećujemo da su adolescenti ženskog pola iz Berana visočiji u odnosu na prosjek (za $1.1 \mathrm{~cm})$. Zbog toga je neophodno izraditi modele visine za svaki dio u Crnoj Gori (Milasinovic, Popovic, Matic, Gardasevic, \& Bjelica, 2016a; Milasinovic, Popovic, Jaksic, Vasilejvic, \& Bjelica, 2016b; Milašinović, Popović, Bjelica, \& Vasiljević, 2016; Popović, Bjelica, Milašinović, \& Gardašević, 2016).

Rezultati regresione analize u ovom istraživanju su poka- zali velike koeficijente korelacije i veliki procenat objašnjenog varijabiliteta, što znači da raspon ruku ima predikativnu vrijednost, odnosno može predvidjeti tjelesnu visinu. U prethodno sprovedenim istraživanjima, utvrđeno je da je kod crnogorskih adolescenata muškog pola raspon ruku $2.5 \mathrm{~cm}$ veći u odnosu na visinu tijela, dok je kod adolescenata ženskog pola tjelesna visna veća za $0.24 \mathrm{~cm}$ (Bjelica i sar.,2017). Prosječna visina muškaraca u Srbiji iznosi $181.96 \mathrm{~cm}$ i imaju raspon ruku od $184.78 \mathrm{~cm}$ dok su žene visoke $166.82 \mathrm{i}$ imaju opseg od $164.67 \mathrm{~cm}$. Kod muškaraca raspon ruku je veći $2.8 \mathrm{~cm}$ $\mathrm{u}$ odnosu na visinu, dok je kod žena raspon ruku manji za $0.15 \mathrm{~cm}$ od visine (Popovic, Bjelica, Molnar, Jaksic, \& Akpinar, 2013). Adolescenti muškog pola u Bosni i Hercegovini su prosječno visoki su $183.84 \mathrm{~cm}$ sa rasponom ruku od $185.65 \mathrm{~cm}$ (Gardasevic i sar., 2017). Takođe, utvđeno je da je kod adolescenata muškog pola tjelesna visina manja za $0.73 \mathrm{~cm}$ u odnosu na raspon ruku, dok je kod adolescenata ženskog pola raspon ruku veći za $1.97 \mathrm{~cm}$ (Popović i sar., 2015). Ukoliko uporedimo ove rezultate sa rezultatima dobijenim u našem istraživanju, uočićemo da su adolescenti muškog pola iz Berana viši od svojih vršnjaka iz Srbije, dok su niži od adolescenata muškog pola iz Bosne i Hercegovine, što nije neobično zbog pretpostavke da najvisočiji ljudi žive na teritoriji Hercegovine. Što se tiče raspona ruku, ženski adolescenti imaju karakteristično manji raspon ruku od visine. Međutim, kod muških adolescenata takođe imamo manji raspon ruku od visine, što nije karakte- 
ristično. Svakako, to potvrđuje potrebu za izradom modela za svaki dio u Crnoj Gori, zbog razlika koje se dobijaju u jednačinama procjene. Takođe, sva ova istraživanja su potrvrdila da raspon ruku pouzdano predviđa visinu tijela.

Na kraju možemo zaključiti da raspon ruku pouzdano predviđa visinu tijela, što se može vidjeti na osnovu rezultata dobijenih linearnom regresionom analizom, gdje je statistička značajnost bila $\mathrm{p}<000$. Odnos između visine tijela i raspona ruku provjeren je i Pearsonovom korelacijskom analizom sa pouzdanošću od $95 \%$. Koeficijenti korelelacije su imali vrlo visoku vrijednost međusobnih korelacija (kod adolescenata muškog pola 0.890 i kod adolescenata ženskog pola 0.789). Ovo upućuje na potrebu ispitivanja tjelesne visine u ostalim gradovima Crne Gore, kako bi se što bolje ispitalo područje Dinarskih Alpa.

\section{Acknowledgements}

There are no acknowledgements

\section{Conflict of Interest}

The authors declare that there are no conflicts of interest.

Received: 21 July 2018| Accepted: 27 August 2018| Published: 29 October 2018

\section{References}

Arifi, F. (2017a). Stature and its estimation utilizing arm span measurements of both gender adolescents from southern region in Kosovo. Sport Science, 10(1), 92-5.

Arifi, F., Bjelica, D., Sermaxhaj, S., Gardasevic, J., Kezunovic, M., \& Popovic, S (2017b). Stature and its Estimation Utilizing Arm Span Measurements in Kosovan Adults: National Survey. International Journal of Morphology, 35(3), 1161-7.

Arifi, F., Gardasevic, J., \& Masanovic, B. (2018). Relationship between foo length measurements and body height: $A$ prospective regional study among adolescents in central region of Kosovo. Sport Mont, 16(3), 7579. doi: $10.26773 / \mathrm{smj} .181013$

Arifi, F., Sermaxhaj, S., Gardasevic, J., Alaj, I., \& Metaj, Z. (2018). Stature and Its Estimation Utilizing Arm Span Measurements of both gender Adolescents from Southern Region in Kosovo. Sport Mont, 16(2), 51-54.

Bjelica, D., Popovic, S., Kezunovic, M., Petkovic, J., Jurak, G., \& Grasgruber P. (2012). Body Height and Its Estimation Utilising Arm Span Measurements in Montenegrin Adults. Anthropol. Noteb., 18(2), 69-83.

Brown, J.K., Feng, J.Y., \& Knapp, T.R. (2002). Is self-reported height or arm span a more accurate alternative measure of height? Clinical Nursing Research, 11(4), 417-32.

Ehrich, R. (1946). A Racial Analysis of Montenegro. Cambridge: Harvard University.

Gardasevic, J. (2018). Relationship between Sitting Height Measurements and Standing Height: A Prospective Regional Study among Adolescents in Eastern Region of Kosovo. Sport Mont, 16(2), 15-19.

Gardasevic, J., Rasidagic, F., Krivokapic, D., Corluka, M., \& Bjelica, D. (2017) Stature and Its Estimation Utilizing Arm Span Measurements in Male Adolescents from Herzeg-Bosnia Entity in Bosnia and Herzegovina. Montenegrin Journal of Sports Science and Medicine, 6(1), 37-44.

Gardasevic, J. (2018). Standing Height/Tibia Length Ration in WesternKosovan Adolescents. Retrieved from SSRN's eLibrary: https://ssrn. com/abstract $=3138101$

Gardasevic, J. (2018b). Standing Height/Sitting Height Ration in EasternKosovan Adolescents. Retrieved from SSRN's eLibrary: https://ssrn com/abstract $=3141566$

Gardasevic, J., Masanovic, B., Arifi, F. (2018a). Relationship Tibia Length/ Standing Height in Central-Kosovan Adolescents. Retrieved from SSRN's eLibrary: https://ssrn.com/abstract=3138122

Gardasevic, J., Masanovic, B., Arifi, F. (2018b). Relationship Tibia Length Standing Height in Northern-Kosovan Adolescents. Retrieved from SSRN's eLibrary: https://ssrn.com/abstract=3138112

Gardasevic, J., Masanovic, B., Arifi, F. (2018c). Relationship Tibia Length/ Standing Height in Southern-Kosovan Adolescents. Retrieved from SSRN's eLibrary: https://ssrn.com/abstract=3138105

Gardasevic, J., Masanovic, B., \& Arifi, F. (2018d). Relationship between tibia length measurements and standing height: A prospective regional study among adolescents in southern region of Kosovo. Sport Mont, 16(3), 51-55. doi: 10.26773/smj.181009
Grasgrber, P., Sebera, P., Hrazdira, J. Cacek, J., \& Kalina, T. (2016). Major correlates of male height: A study of 105 countries. Economic\&Human Biology, 21, 172-195.

Masanovic, B. (2017). Relationship between arm span measurements and body height in Dinaric Alpes population: A systematic review. Journal of Anthropology of Sport and Physical Education, 1(1), 33-37.

Masanovic, B. (2018). Standing Height and its Estimation Utilizing Arm Spam and Foot Length Measurements in Dinaric Alps Population: A Systematic Review. Sport Mont 16(2), 1-6.

Masanovic, B. (2018a). Tibia Length and Standing Heigh Relationshipt in Eastern Region of Kosovo. Retrieved from SSRN's eLibrary: https://ssrn. com/abstract $=3143118$

Masanovic, B., Gardasevic, J., \& Arifi, F. (2018a). Relationship between foot length measurements and body height: $A$ prospective regional study among adolescents in eastern region of Kosovo. Sport Mont, 16(1), 9-13. doi: $10.26773 /$ smj.180202

Masanovic, B., Gardasevic, J., \& Arifi, F. (2018b). Relationship between Foot Length Measurements and Body Height: A Prospective Regional Study among Adolescents in Northern Region of Kosovo. AnthropologieInternational Journal of Human Diversity and Evolution, in pres, https:// doi.org/10.26720/anthro.18.01.23.1

Masanovic, B., Gardasevic, J., \& Arifi, F. (2018c). Relationship between Foot Length Measurements and Body Height: A Prospective Regional Study among Adolescents in Central Region of Kosovo. Journal of Contemporary Medical Sciences, in press

Masanovic, B., Gardasevic, J., \& Arifi, F. (2018d). Standing Height and its Estimation Utilizing Foot Length Measurements in Adolescents from Southern Region in Kosovo. Sport Mont, 16(2), 27-31. doi: 10.26773/ smj. 180605

Masanovic, B. (2018a). Standing Height/Sitting Height Relationhip in Western Region in Kosovo. Retrieved from SSRN's eLibrary: https://ssrn. com/abstract $=3138518$

Masanovic, B., Gardasevic, J., \& Arifi, F. (2018e). Sitting Height/Standing Height Relationship in Southern Region of Kosovo. Retrieved from SSRN's eLibrary: https://ssrn.com/abstract=3138523

Masanovic, B., Gardasevic, J., \& Arifi, F. (2018f). Sitting Height/Standing Height Relations in Central Region of Kosovo. Retrieved from SSRN's eLibrary: https://ssrn.com/abstract=3138525

Masanovic, B., Gardasevic, J., \& Arifi, F. (2018g). Sitting Height/Standing Height Relationship Measurements in Northern Region of Kosovo. Retrieved from SSRN's eLibrary: https://ssrn.com/abstract=3138526

Milašinović, R., Popović, S., Bjelica, D., \& Vasiljević, I. (2016). Body height and its estimation utilizing arm span measurements in female adolescents from northern region in Montenegro. In Book of Abstracts of 4th International Scientific Conference "Exercise and Quality of Life" (39), Novi Sad: Faculty of Sport and Physical Education.

Milasinovic, R., Popovic, S., Matic, R., Gardasevic, J., \& Bjelica, D. (2016a). Body Height and its Estimation Utilizing Arm Span Measurements in Male Adolescents from Southern Region in Montenegro. Sport Mont, 14(2), 21-3.

Milasinovic, R., Popovic, S., Jaksic, D., Vasiljevic, I., \& Bjelica, D. (2016b). Stature and its Estimation Utilizing Arm Span Measurements in Feale Adolescents from Southern Region in Montenegro. Sport Mont, 14(3), $15-8$.

Quanjer, P.H., Capderou, A., Mazocioglu, M.M., Aggarwal, A., Popovic, S., Datta Banik, S., Tayie, F. A.K., Golshan, M., Ip, M.S.M., \& Zelter, M. (2014). All-age relationship between arm span and height in different ethnic groups. European Respiratory Journal, 44, 905-12.

Pineau, J.C., Delamarche, P., \& Bozinovic, S. (2005). Average height of adolescents in the Dinaric Alps. C. R. Biol., 328(9), 841-6.

Popovic, S. (2016). Body Height and its Estimation Utilizing Arm Span Measurements in Montenegrin Adults: National Survey. In Book of Summaries of 11th FIEP European Congress "Anthropological Aspects of Sport, Physical Education and Recreation" (5-6), Banjaluka: University of Banjaluka, Faculty of Physical Education and Sport.

Popovic, S. (2017). Local Geographical Differences in Adult Body Height in Montenegro. Montenegrin Journal of Sports Science and Medicine, 6(1), 81-7.

Popovic, S., Arifi, F., \& Bjelica, D. (2017a). Standing Height and its Estimation Utilizing Foot Length Measurements in Kosovan Adults: National Survey. International Journal of Applied Exercise Physiology, 6(2), 1-7.

Popovic, S., \& Bjelica, D. (2016). Body Height and its Estimation Utilizing Arm Span Measurements in Kosovan Adolescence: National Survey. In Abstract Book of International Eurasian Conference on Sport, Education, and Society (9), Antalya: International Science Culture and Sport Association.

Popovic, S., \& Bjelica, D. (2017). Body Height and its Estimation Utilizing Foot Length Measurements in Kosovan Adults: National Survey. In Abstract 
Book of the Sport Science Conference AESA 2017 (2), Amol: Faculty of Sport Sciences, Shomal University; Asian Exercise and Sport Science Association.

Popovic, S., Bjelica, D., Georgiev, G., Krivokapic, D., \& Milasinovic, R. (2016). Body Height and its Estimation Utilizing Arm Span Measurements in Macedonian Adults. Anthropologist, 24(3), 737-745.

Popovic, S., Bjelica, D., Molnar, S., Jaksic, D., \& Akpinar, S. (2013). Body Heigh and Its Estimation Utilizing Arm Span Measurements in Serbian Adults. International Journal of Morphology, 31(1), 271-279.

Popovic, S., Bjelica, D., Tanase, G.D. \& Milasinovic, R. (2015). Body Height and Its Estimation Utilizing Arm Span Measurements in Bosnian and Herzegovinian Adolescents. Montenegrin Journal of Sports Science and Medicine, 4(1), 29-36.

Popovic, S. Gardasevic, J., Masanovic, B., Arifi, F., \& Bjelica, D. (2017b). Standing Height and its Estimation Utilizing Foot Length Measurements in Adolescents from Western Region in Kosovo. Sport Mont, 15(3), 3-7.

Popović, S., Bjelica, D., Petković, J., Muratović, A. \& Georgiev, G. (2014). Body Height and Its Estimation Utilizing Arm Span Measurements in Macedonian Adolescents. In Abstract Book of the 7th Conference for Youth Sport (40), Ljubljana: Faculty of Sport, University of Ljubljana.

Popović, S., Milašinović, R., Matić, R., Gardašević, J., Bjelica, D. (2016). Body height and its estimation utilizing arm span measurements in male adolescents from southern region in Montenegro. In Book of Abstracts of the 13th International Scientific Conference on Transformation Process in Sport "Sport Performance" (29-30), Podgorica: Montenegrin Sports Academy.

Popović, S., Milašinović, R., Jakšić, D., Vasiljević, I., Bjelica, D. (2016). Body height and its estimation utilizing arm span measurements in female adolescents from southern region in Montenegro. In Book of Abstracts of the 13th International Scientific Conference on Transformation Process in Sport "Sport Performance" (30), Podgorica: Montenegrin Sports Academy.

Popović, S., Bjelica, D., Milašinović, R., \& Gardašević, J. (2016). Body height and its estimation utilizing arm span measurements in male adolescents from northern region in Montenegro. In Book of Abstracts of 4th International Scientific Conference "Exercise and Quality of Life" (38), Novi Sad: Faculty of Sport and Physical Education.

Popović, S., Bjelica, D., Milašinović, R., Gardašević, J., \& Rašidagić, F. (2016). Body height and its estimation utilizing arm span measurements in male adolescents from Herzeg-Bosnia entity in Bosnia and Herzegovina. In Book of Abstracts of IUAES Inter Congress "World anthropologies and privatization of knowledge: engaging anthropology in public" (148), Dubrovnik: International Union of Anthropological and Ethnological Sciences.

Popovic, S. \& Bjelica, D. (2016). Body Height and its Estimation Utilizing Arm Span Measurements in Kosovan Adolescence: National Survey. In Abstract Book of International Eurasian Conference on Sport, Education, and Society (9), Antalya: International Science Culture and Sport Association.

Reeves, S.L., Varakamin, C., \& Henry, C.J. (1996). The relationship between armspan measurement and height with special reference to gender and ethnicity. Eur. J. Clin. Nutr., 50(6), 398-400.

Steele, M.F., \& Chenier, T.C. (1990). Arm-span, height, and age in black and white women. Ann. Hum. Biol., 17(6), 533-41. 